\title{
Singuagens
}

\section{"SISTEMA": RELAÇÕES ENTRE AS PERSPECTIVAS DE SAUSSURE E DA GRAMÁTICA SISTÊMICO-FUNCIONAL DE HALLIDAY}

\author{
Ana Paula Carvalho Schmidt (UFSM) \\ Helena Selbach (UFSM)
}

\begin{abstract}
RESUMO: O Curso de Línguística Geral (CLG), compilação organizada pelos linguistas Albert Sechehaye e Charles Bailly, pode ser considerada a obra fundante da Linguística apesar das críticas e concordâncias que recebeu desde a publicação da primeira edição em 1916. Neste artigo, a partir de um trabalho inscrito no âmbito dos Estudos Linguísticos e desenvolvido no Programa de Pós-Graduação da Universidade Federal de Santa Maria, propomos um diálogo entre as perspectivas de Ferdinand de Saussure e de M. A. K. Halliday. Nosso objetivo é verificar como o conceito de "sistema" é concebido na perspectiva saussuriana e na hallidiana para investigar em que medida essas perspectivas se aproximam e/ou se distanciam, pois esse conceito mostra-se relevante em ambas. As perspectivas parecem se aproximar quanto a) ao papel das escolhas léxico-gramaticais na construção de significado, b) à língua como um sistema de linguagem, e c) à noção de sincronia versus diacronia.
\end{abstract}

PALAVRAS-CHAVE: Ferdinand de Saussure; M. A. K. Halliday; Sistema; Significado.

ABSTRACT: Curso de Línguística Geral (CLG), a compilation organized by linguists Albert Sechehaye and Charles Bailly, can be considered the founding work of Linguistics despite both criticism and concordances received since the publication of its first edition in 1916. In this article, situated in the realm of Linguistic Studies and developed in the Post-Graduation Program of the Federal Univresity of Santa Maria, we propose a dialogue between Ferdinand de Saussure's and M. A. K. Halliday's perspectives. We aim at investigating the concept of "system" in the Saussurian perspective as well as in Halliday' Systemic-Functional Grammar in order to discuss to what extent these two approaches are linked and/or differ since this concept is relevant for both works. Both approaches seem to have in common the following aspects: a) the role of the lexicogrammatical choices to build meaning, b) the language as one language system, and c) the concept of sincrony versus diacrony.

KEYWORDS: Ferdinand de Saussure; M. A. K. Halliday; System; Meaning.

\section{INTRODUÇÃO}

Historicamente, há uma diversidade de estudos que buscam compreender e organizar as línguas humanas, por exemplo, o estudo normativo da língua na Gramática, a interpretação e comparação entre textos de diferentes épocas na Filologia ou ainda a comparação entre as línguas a fim de explicar uma pela outra, na Gramática Comparativa (SAUSSURE, 1975).

Nessas três perspectivas, contudo, não se buscava interpretar as implicações desses estudos comparativos. Fruto dos estudos românicos e germânicos (Idem, p. 11), a Linguística emergiu no século XIX e, no final desse século, um grupo dos neogramáticos reuniu-se na Alemanha com o propósito de colocar os estudos comparativos em uma perspectiva histórica (Ibid). É nesse contexto que o linguista suíço Ferdinand de Saussure [1857-1913] desenvolve Linguagens \& Cidadania, v. 19, número especial, jan./dez., 2017. 


\section{Linguagens}

os estudos sobre os problemas até então não elucidados sobre a ciência da língua. Saussure constrói uma linguística que possui metodologia e objetos próprios dentro de uma visada interdisciplinar na qual a Semiologia e a Psicologia Social têm espaço (CAMPOS; STREY, 2014, p. 578). O Curso de Linguística Geral "fundou a Linguística e serviu de base para o estabelecimento de uma epistemologia para as Ciências Humanas" (FIORIN, 2014, p. 55); as categorias saussurianas, por sua vez, "(...) - em forma de dicotomias - continuam subjacentes à produção científica dos atuais estudiosos da linguagem, às vezes reformuladas, às vezes enriquecidas, mas sempre presentes"1 (OLIVEIRA, 2014, p. 38).

Por volta de meio século mais tarde, M. A. K. Halliday publicava seu trabalho seminal sobre a teoria linguística que ficou conhecida mais tarde como Linguística SistêmicoFuncional (LSF) na qual estabelecia relações entre língua, texto e contexto e para qual o conceito de "sistema", entre outros, é fundamental.

$\mathrm{Na}$ literatura, há pesquisas que tecem relações entre conceitos saussurianos e, por exemplo, 1) a análise multimodal do discurso (RAVELLI, 2014), 2) a linguística de corpus (SARDINHA, 2014) e 3) teorias cognitivas sobre memória e linguagem (THIBAULT, 2014). Neste artigo, propomos um diálogo entre as perspectiva de Saussure e de Halliday: nosso objetivo é verificar como o conceito de "sistema" é concebido na perspectiva saussuriana e na da Gramática Sistêmico-Funcional hallidiana de forma a investigar em que medida essas duas perspectivas se aproximam e/ou se distanciam. Para tanto, apresentamos, nas duas próximas seções, as perspectivas saussuriana e hallidiana separadamente para, na quarta seção, delinearmos as aproximações e distanciamentos entre as mesmas.

\section{A PERSPECTIVA SAUSSURIANA}

O Curso de Línguística Geral (CLG), compilação organizada pelos linguistas Albert Sechehaye e Charles Bailly, tem sido alvo de críticas e concordâncias desde a publicação de sua primeira edição em 1916. Uma das críticas mais persistentes diz respeito à atribuição de

\footnotetext{
${ }^{1}$ Disciplinas como a Análise do Discurso, Linguística do Texto ou Análise da Conversação, [que] "precisam "descer" a níveis microestruturais, entrando nos domínios da morfologia, da sintaxe e da fonologia, se o fizerem insensíveis às categorias "inauguradas" por Saussure, cometerão falhas metodológicas e epistemológicas" (OLIVEIRA, 2014, p. 38).
} 


\section{Singuagens}

autoria da obra à Ferdinand de Saussure (BOUQUET, 2009). Os próprios Sechehaye e Bailly advertem, no prefácio à primeira edição, que a publicação de todos os ensinamentos orais em livro revelou-se uma tarefa impossível, pois "les redites, inévitables dans un exposé libre, les chevauchements, les formulations variable auraient donné à une telle publication une aspecte

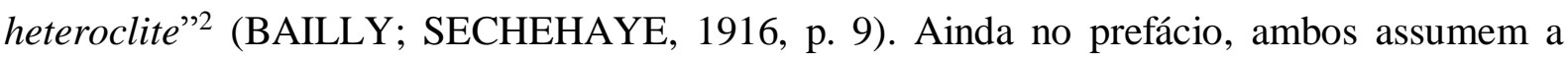
responsabilidade perante a crítica e a interpelam: "la critique saura-t-elle distinguer entre le maître et ses interprètes?"3 (idem, p. 11). Apesar de não ser uma transcrição exata das palavras proferidas por Saussure durante as aulas, e sim uma edição e compilação dos referidos autores que uniram peças de um quebra-cabeça, fornecidas por seus ex-alunos e pela viúva, Mme. Saussure, há de se reconhecer que é por meio do CLG que tomamos conhecimento de parte do pensamento saussuriano (NORMAND, 2009, p. 24).

A interpretação do $C L G$ pode estar vinculada a uma "tradição" e a quatro fases distintas de recepção da obra (SARGENTINI; BARONAS, 2007, p. 44-45 com base em PUECH, 2005). A primeira recepção relaciona-se à época em que a obra foi publicada, momento em que houve marginalização das ideias do $C L G$; a segunda, em 1928 , ao $1^{\circ}$ Congress International des Linguistes à La Haye, quando Saussure começa a ser reconhecido como fundador de uma Linguística autônoma. No contexto de pós-guerra, que caracteriza a terceira fase, a leitura de Saussure é ampliada e difundida em outras disciplinas como a Sociologia, a Antropologia e a Filosofia. O termo "estruturalismo" se fixa, bem como uma leitura do estruturalismo caracterizado por dicotomias. A quarta recepção, por fim, caracteriza-se por estudos a partir da década de 60 , a qual volta-se aos estudos críticos e às fontes manuscritas, na busca por um "verdadeiro pensamento de Saussure" (Ibid, p. 44). Com base em Chiss e Puech (1994), Sargentini e Baronas (p. 45) ressaltam ainda que "as referências ao Saussure "fundador" parecem mais ter como função garantir sua unidade que

\footnotetext{
2 “(...) as repetições, inevitáveis em uma exposição livre, as sobreposições, as formulações variáveis teriam dado à uma tal publicação um aspecto heteróclito.” Esta tradução, bem como as demais presentes neste trabalho, são de responsabilidade das autoras deste artigo.

3 “Saberá a crítica distinguir entre o mestre e seus intérpretes?"

${ }^{4}$ Muitos dos manuscritos de Saussure da década de 1890 foram descobertos cem anos depois de sua escrita (SILVEIRA, 2014, p. 27) e são objeto de estudo de linguistas contemporâneos.
}

Linguagens \& Cidadania, v. 19, número especial, jan./dez., 2017. 


\section{Singuagens}

seguir uma filiação. Os autores (Idem), com base em Pêcheux (1999), apontam que a teoria de Saussure, em diferentes momentos, "expressa um posicionamento e um partidarismo em relação às condições históricas de cientificidade da linguística".

Para Saussurre (1975, p. 13), toda manifestação escrita da linguagem humana em diferentes épocas interessa à Linguística, cabendo a ela 1) descrever a história de todas as línguas, 2) propor leis gerais que regem as famílias de línguas e, também, 3) delimitar e definir a si própria a fim de explicitar e eliminar enganos formulados por estudiosos de outras áreas ${ }^{5}$ :

(...) uma ciência que estude a vida dos signos no seio da vida social". (...) Ela nos ensinará em que consistem os signos, que leis os regem" (...). A tarefa do linguista é definir o que faz da língua um sistema especial no conjunto dos fatos semiológicos" (SAUSSURE, p. 1975, p. 24).

Nessa perspectiva, a língua, objeto de estudo da Linguística, é considerada "um sistema do qual todas as partes podem e devem ser consideradas em sua solidariedade sincrônica" (SAUSSURE, 1975, p. 102). Por solidariedade sincrônica, entendemos a relação de interdependência entre os elementos da língua que os une ao sistema.

Com base na obra A Vida da Linguagem de Whitney (1875), Saussure se diferencia das escolas que o precederam ao apontar que a língua pertence à ordem do social. $\mathrm{O}$ conceito de fato social ${ }^{6}$, vigente no contexto histórico de Saussure, diverge, segundo Sargentini e Baronas (2007, p. 46), do conceito de outros estudiosos da época. Para Saussure, "a natureza social da língua" constitui uma de suas características internas e é esse fato que possibilita a concepção de uma ciência que se debruça sobre "a vida dos signos no interior da vida social: a semiologia" (Idem). Isso significa, por exemplo, considerar como objeto de estudo os usos que os locutores fazem do sistema da língua - o significado em uso. Apesar de não oferecerem explicação para determinadas escolhas de uso, os locutores demonstram conhecimento destes saberes na prática (NORMAND, 2000, p. 46). Flores (2008, p. 157)

\footnotetext{
${ }^{5}$ Sem perder de vista a complexidade envolvida na discussão sobre autoria do CLG, tomaremos, neste trabalho, o mesmo como exemplar da obra de Saussure.

${ }^{6}$ Termo originalmente cunhado na Sociologia, por Émile Durkheim, em As regras do método sociológico.
} 


\section{Singuagens}

ressalta que, para Saussure, é a relação com a língua que garante o estudo da atividade de quem fala em um conjunto de disciplinas que possuem um lugar na Linguística, razão pela qual Saussure propõe que a linguagem seja estudada em duas partes distintas: a língua (parte social da linguagem) e a fala (sua parte individual). Essa dicotomia "langue/parole" (língua e fala):

(...) continua operacionalmente válida no que tem de essencial, a saber, na distinção entre o que na linguagem é código (langue) e o que é mensagem (parole). Podemos produzir e interpretar mensagens (isto é, textos orais e escritos) porque temos em nossa mente um código, ou seja, a langue, o sistema da língua (OLIVEIRA, 2014, p. 40).

Nesse viés, o sistema desses falares compartilhados é um fato da linguagem que cria o sistema linguístico, pois é a comunidade de falantes que estabelece os valores arbitrários por meio de um contrato tácito: as mudanças na fala de um só indivíduo não corroboram para a mudança no todo. O aspecto social da linguagem é uma constante no $C L G$, bem como a noção de sistema e os termos a ela relacionados parecem reveladores dos princípios fundamentais da proposta saussuriana para o estudo da língua. Flores (2008) aponta que a definição de língua, sob a perspectiva saussuriana, envolve eliminar "tudo o que seja estranho ao sistema": tais elementos, portanto, passam a pertencer à "Linguística externa" ou à "linguística da fala" e não constituem o objeto de estudo da linguística proposta por Saussure ${ }^{7}$.

Saussure, no $C L G$, delimita a diferença entre "linguagem", "língua" e "fala" e elege "a língua a partir do ponto de vista de sua estrutura, de sua organização interna, de seu caráter sistêmico" como objetivo central de seu estudo (SARGENTINI; BARONAS, 2007, p. 49-50). A língua é composta de unidades básicas que se relacionam entre si e a unidade, por sua vez, recebe a denominação de signo linguístico; compõe-se das faces "conceito" e "imagem mental do conceito, sua imagem acústica" que, ao unirem-se em uma "associação psíquica"

\footnotetext{
${ }^{7}$ Flores (2008, p. 158) ressalta o estatuto da "Linguística externa", também chamada de linguística da fala no $C L G$ : "Saussure (...) impõe a escolha ou do caminho da língua, ou do caminho da fala. Essa necessidade de escolha, porém, não impede Saussure de admitir a importância dos estudos da fala, pois as relações da língua com a etnologia, com a história política e com as instituições (igreja, escola, etc.) apenas poderiam, segundo ele, ser contempladas pela "Lingüística externa". Em testemunho disso há o capítulo 5 da Introdução do CLG, Elementos internos e elementos externos da língua. Aliás, nunca é demais lembrar: Saussure confere os status de linguística ao estudo da fala, ele o denomina de "linguística da fala".
} 


\title{
S Linguagens
}

no cérebro dos indivíduos, formam o "significado" e o "significante" em uma relação arbitrária, não-natural entre essas duas faces (Idem). Oliveira (2014, p. 43) aponta que, para Saussure, o conceito de signo linguístico é

\begin{abstract}
a associação de um significante (de natureza sonora) a um significado (a que ele frequentemente se refere como uma "ideia"), ressaltando que o significante não é o som como realidade física nem o significado equivale exatamente ao caleidoscópico conjunto de pessoas e coisas do mundo, acrescentando que, tanto os sons quanto as "ideias", são um continuum nebuloso. O continuum dos sons é a substância do significante e o das "ideias" é a substância do significado. O que funciona na língua, contudo, são os sons estruturados (ou forma do significante) e os conceitos estruturados (ou forma do significado).
\end{abstract}

A língua, compreendida como produto da sociedade, "a natureza social da linguagem", tende à manutenção e à estabilidade, "defender[ndo]-se da inovação"; é adquirida de forma análoga a uma herança, sendo os vínculos com o passado mais fortes do que a inovação linguística, característica essa que não impede a produção de movimentos e deslocamentos da língua que "afetem a relação significado-significante" (Ibid).

A partir dos conceitos discutidos nesta seção, elaboramos as Fig. 1 e 2 a fim de apresentar, respectivamente, um mapa semântico do conceito de língua e do conceito de sistema com base em Saussure (1975).

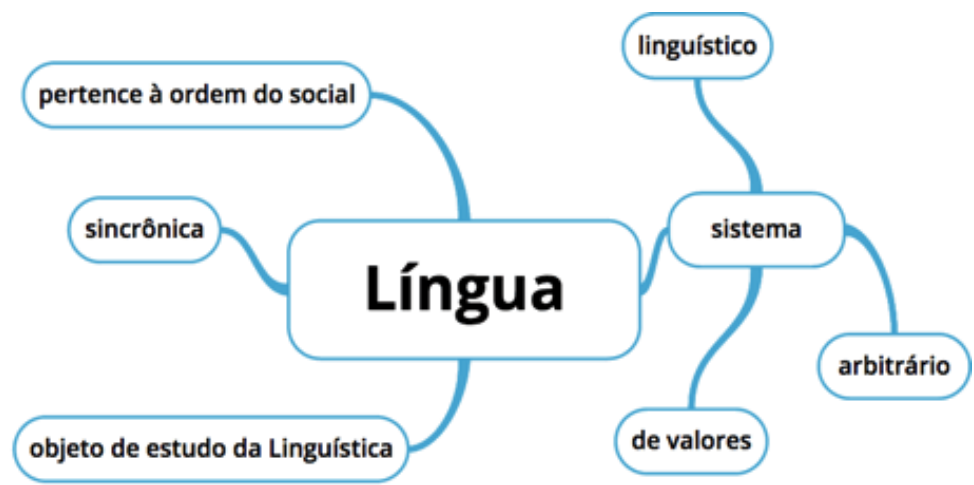

Figura 1- Mapa semântico do conceito de língua com base em Saussure (1975). 


\section{Linguagens \& Cidadania}

Conforme a Fig. 1, língua é conceituada no CGL como um sistema 1) linguístico, 2) arbitrário de valores, 3) sincrônico e 4) pertencente à ordem do social, 5) o qual constitui o objeto de estudo da Linguística ${ }^{8}$.

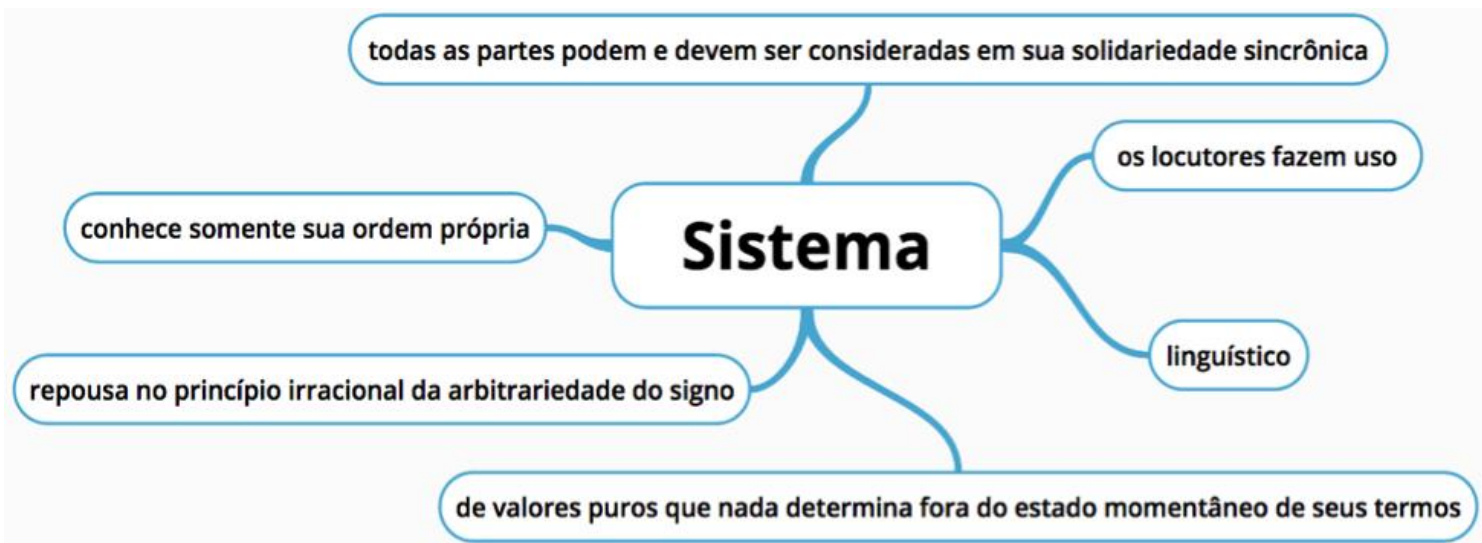

Figura 2 - Mapa semântico do conceito de sistema com base em Saussure (1975).

De acordo com a Fig. 2, o sistema da língua do qual os locutores se utilizam é 1) linguístico, 2) arbitrário, pois "repousa no princípio irracional da arbitrariedade do signo" (SAUSSURE, 1975, p. 154), "conhece somente sua ordem própria", o que estabelece a Linguística como um campo de estudo autônomo em relação às demais ciências (Ibid., p. 31), 3) de valores sincrônicos que "nada determina fora do estado momentâneo de seus termos" (Ibid., p. 95), 4) e cujas partes "devem ser consideradas em sua solidariedade sincrônica" (Ibid, p. 102).

$\mathrm{Na}$ seção seguinte, apresentamos a perspectiva hallidiana que informa o conceito de "sistema" a partir da Linguística Sistêmico-Funcional, na qual a Gramática SistêmicoFuncional se inscreve.

\section{A PERSPECTIVA HALLIDIANA}

\footnotetext{
${ }^{8}$ Flores (2008, p. 158), chama a atenção para a clareza de Saussure, que, ao determinar a língua como objeto de estudo da linguística, não descuidou-se 1) do momento histórico voltado à cientificidade no qual estava inserido e 2) da fala que "problematizava a regularidade do objeto construído": "(...) de um lado, com a determinação da língua como objeto da linguística, Ferdinand de Saussure parece trazer paz aos corações aflitos do início do século XX, que clamavam por um objeto tangível e regular; de outro lado, não se pode ignorar que Saussure não desconhecia que a fala, ou aquilo que não cabia na definição de língua, problematizava a regularidade do objeto construído".
} 


\section{Singuagens}

Fuzer e Cabral (2014), ao apontarem o percurso percorrido pela Linguística SistêmicoFuncional (LSF), na qual a Gramática Sistêmico-Funcional (GSF) está inscrita, e tem em M. A. K. Halliday seu principal expoente, remetem as origens dessa perspectiva às pesquisas do antropólogo Bronislaw Malinowski [1884-1932], as quais conferiram à língua o estatuto de "uma das mais importantes manifestações da cultura de um povo" (FUZER; CABRAL, 2014, p. 17).

O estabelecimento dessa relação entre língua e uso em contexto veio a influenciar o trabalho do linguista John Rupert Firth [1890-1960] que iniciou as sistematizações vinculadas a esses princípios. Seu orientando, o linguista britânico M. A. K. Halliday [1925], na década de 1960, deu seguimento aos estudos de seu mentor, desenvolvendo uma "abordagem de análise gramatical denominada Gramática de Escala e Categorias". Halliday credita a Saussure o estabelecimento do princípio paradigmático, "cujo conceito de valor e, em termos em um sistema, mostrou a organização paradigmática mais abstrata do significado" (HALLIDAY, 2006, p. 11) ${ }^{9}$. Em 1985, publicou An Introduction to Functional Grammar que foi editada em 1994, 2004 (ano em que Christian M. I. M. Matthiessen começou a colaborar) e em 2014 (Ibid). ${ }^{10}$

A GSF caracteriza-se como "uma teoria sociossemiótica (...) que prioriza a íntima relação léxico-gramática em interface com a semântica e o discurso" (FUZER; CABRAL, 2014, p. 14). Nomeia-se: 1) sistêmica", por entender a língua como "redes de sistemas linguísticos interligados, das quais nos servimos para construir significados" e agir no mundo. Cada um dos sistemas constitui-se em um conjunto de possibilidades semânticas, léxicogramaticais ou fonológicas e grafológicas e 2) funcional, por "explica[r] as estruturas

9 “(...) whose concept of value, and of terms in a system, showed up paradigmatic organization as the most abstract dimension of meaning (...) (HALLIDAY, 2006, p. 11).

10 Thompson e Collins (2001, p. 135) apontam ainda que na década de 1960, Halliday explorou a produção de Chomsky e trabalhou com professores em todos os níveis, envolvendo-se no desenvolvimento de uma gramática para fins educativos.

11 Uma vez que nosso interesse de pesquisa recai sobre as aproximações e/ou distanciamentos entre as perspectivas saussurianas e hallidianas acerca do conceito de "sistema", nosso foco de análise será nas ocorrências desses termos nas obras CLG e An Introduction to Functional Grammar. 


\section{Singuagens}

gramaticais em relação ao significado", às funções desempenhadas pela linguagem nos textos (Ibid, p. 19, grifos das autoras).

A teoria sistêmico-funcional, ao "busca[r] identificar as estruturas de linguagem específicas que contribuem para o significado de um texto", contribui para análises "que se propõem a demonstrar como e por que um texto significa o que significa" (FUZER; CABRAL, 2014, p. 19 com base em Webster, 2009).

"Sistema" difere-se conceitualmente da noção de "estrutura" (FUZER; CABRAL, 2014). "Estrutura" inscreve-se, na perspectiva da GSF, como o "ordenamento sintagmático na linguagem: padrões ou regularidades, que respondem à pergunta "o que vai junto com o quê?"; "sistema", por sua vez, é definido como "o ordenamento paradigmático da linguagem: padrões ou regularidades, que respondem à pergunta "o que pode figurar em lugar de quê?" (Ibid, 2014, p. 21, grifos das autoras). Um sistema é constituído, dessa forma, por qualquer conjunto de alternativas (Ibid).

"Language is, in the first instance, a resource for making meaning; so text is a process of making meaning in context ${ }^{12}$ ". Na perspectiva sistêmico-funcional, a língua é explorada em termos funcionais, a partir do ângulo em que expressa e produz significado (HALLIDAY; MATTHIESSEN, 2014, p. 3). Como sistema ("um processo contínuo de eleição semântica"), a língua se instancia em textos (FUZER, CABRAL, 2014, p. 22 com base em GOUVEIA, 2008). O conceito de "texto" diz respeito à "any instance of language, in any medium, that makes sense to someone who knows the language ${ }^{13 "}$ (HALLIDAY; MATTHIESSEN, 2014, p. 3).

Em uma perspectiva sistêmico-funcional, a linguagem é compreendida como "um tipo particular de sistema semiótico que se baseia na gramática, caracterizada pela organização em estratos e pela diversidade funcional" (FUZER; CABRAL, 2014, p. 21). O sistema de significados - a semântica - realiza-se pelo sistema de fraseado (a léxico-gramática), que, por sua vez, realiza-se pela fonologia (sistema de sonoridade) e grafologia (sistema de grafia),

\footnotetext{
12 “A língua é, em primeira instância, um recurso para produzir significado; assim, o texto é um processo de produção de significado em contexto.”

13 “qualquer instância da língua, em qualquer meio, que faz sentido para alguém que conhece a língua”.
} 


\section{Singuagens}

sistemas esses que são interdependentes e estão envolvidos pelo contexto (Ibid). As escolhas linguísticas dos falantes, a partir do "sistema de opções válidas" - a gramática da língua - não ocorrem in vácuo e, sim, no "contexto de situação da fala" (Ibid, p. 26, com base em Halliday, 1978).

O texto, por sua vez, é compreendido como um produto de instanciação (uma vez que o sistema de uma língua [seu potencial como um recurso de produção de significado] é "instanciado" na forma de texto) (HALLIDAY; MATTHIESSEN, 2014, p. 27, grifos dos autores) e de realização. É também um produto de realização, uma vez que temos acesso somente ao "texto como realizado em som ou escrita"), (Ibid, p. 51, grifos dos autores) e não, diretamente, às instâncias de linguagem em estratos mais altos, como, por exemplo, seleções de significado ou fraseado.

A língua ${ }^{14}$, compreendida como responsável pela construção da experiência humana, "fornece uma teoria" dessa experiência, realizada pela Metafunção Ideacional. Essa metafunção divide-se nos componentes experiencial e lógico (HALLIDAY; MATTHIESSEN, p. 30, grifos dos autores). A função experiencial, "responsável pela construção de um modelo de representação do mundo" (material ou da consciência humana), possui a oração (vista como representação) como unidade de análise. Já a função lógica, "responsável pelas combinações de grupos lexicais e oracionais", tem no complexo oracional sua unidade de análise (FUZER; CABRAL, 2014, p. 33).

Simultaneamente, a língua: 1) representa nossas relações sociais e pessoais - é a "linguagem como ação" - realizada pela Metafunção Interpessoal e 2) apresenta "outro modo de significado que se relaciona com a construção do texto" - uma função facilitadora em relação às demais, denominada Metafunção Textual (HALLIDAY; MATTHIESSEN, p. 30, grifos dos autores).

Halliday e Hasan (1989), ao apontarem o caráter essencialmente multifuncional da língua, enfatizam que suas funções ocorrem simultaneamente e que não é possível apontarmos a existência de uma única função em um dado segmento da língua. Os autores recomendam

\footnotetext{
14 Apesar dos termos língua e linguagem serem utilizados intercambiavelmente em alguns momentos do texto tendo em vista a tradução do termo "language" como "língua" e "linguagem", ressaltamos que Halliday e Hasan (1989, p. 4) e Halliday e Matthiessen (2014, p. 20) fazem essa distinção, ao definir língua como natural, humana, adulta e verbal, em oposição a outras linguagens como a matemática, a música e a arte.
} 


\section{Linguagens \& Cidadania}

que, simultaneamente e a partir de ângulos diferentes, olhemos "these strands [experiential, interpersonal, logical e textual] of meaning [that] are all interwoven in the fabric of discourse ${ }^{15 "}$ a fim de que cada perspectiva dê a sua contribuição para a interpretação global (HALLIDAY; HASAN, 1989, p. 23).

A Fig. 3 apresenta um mapa semântico de língua a partir da perspectiva sistêmicofuncional hallidiana e a Fig. 4, um mapa semântico do conceito de sistema dentro dessa mesma perspectiva.

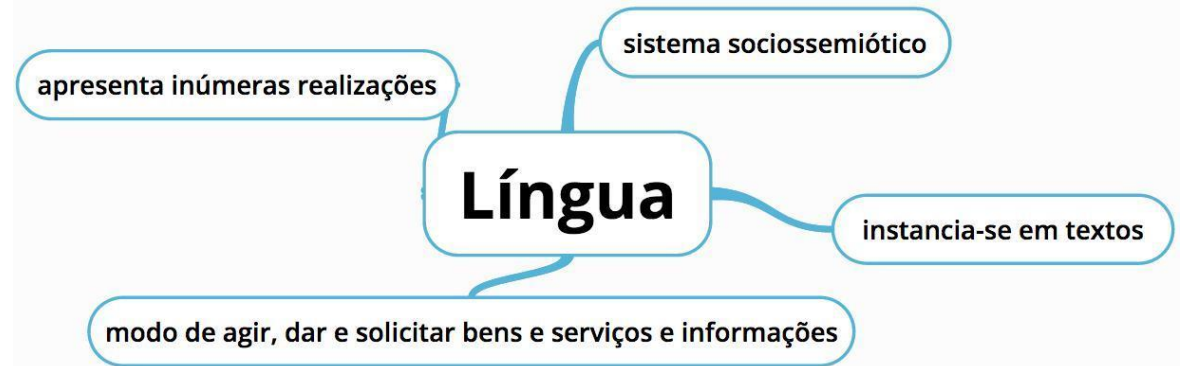

Figura 3 - Mapa semântico da perspectiva sistêmico-funcional de língua com base em Halliday e Matthiessen (2014) e Fuzer e Cabral (2014).

No mapa semântico da Fig. 3, observamos que a língua, na perspectiva hallidiana, é instanciada, isto é, materializada, por meio de textos autênticos (THOMPSON; COLLINS, 2001, p. 145). Ela também apresenta diferentes formas de realização que se dão pela relação estabelecida entre os estratos que a organizam - fonético, fonológico, léxico-gramatical e semântico (HALLIDAY; MATTHIESSEN, 2014, p. 26). Caracteriza-se, também, por ser um sistema sociossemiotico, pois envolve o estudo do significado do qual a estrutura social é constitutiva. É um modo de ação no mundo, bem como um modo de dar e solicitar bens e serviços e informações.

\footnotetext{
15 "esses fios [experienciais, interpessoais, lógicos e textuais] de significado [que estão] interligados no tecido do discurso".
}

Linguagens \& Cidadania, v. 19, número especial, jan./dez., 2017. 


\section{S Linguagens}

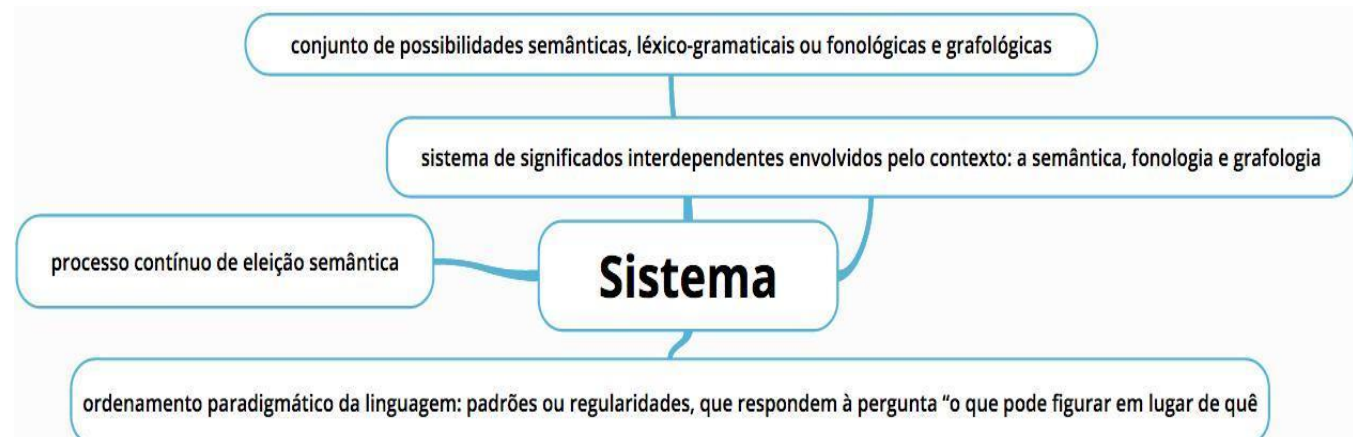

Figura 4 - Mapa semântico do conceito de "sistema"

com base em Halliday e Matthiessen (2014) e Fuzer e Cabral (2014).

De acordo com a Fig. 4, sistema, na perspectiva hallidiana, é compreendido como um conjunto de possibilidades semânticas, léxico-gramaticais ou fonológicas e grafológicas que é continuamente realizado pelas escolhas dos falantes de uma língua, ao mesmo tempo que constitui-se em um sistema de significados composto pela semântica, fonologia e grafologia, sistemas esses que são interdependentes e estão envolvidos pelo contexto.

\section{POSSÍVEIS RELAÇÕES}

Neste artigo, ao analisarmos o conceito de "sistema" como base dos paradigmas teóricos saussuriano e hallidiano, a fim de mapear possíveis aproximações e/os distanciamentos presentes, identificamos, nesse processo de investigação, três pontos de convergência voltados: a) às relações sintagmáticas versus relações associativas e o papel das escolhas léxico-gramaticais, b) à língua como um sistema de linguagem e c) à sincronia versus diacronia.

Saussure (1975), no quinto capítulo do CGL, relações sintagmáticas e relações associativas, argumenta que podem existir dois tipos de relações entre os termos de uma oração. No nível do discurso, a ordem dos sintagmas gera uma relação de coexistência, na qual os termos ocorrem in praesentia, um após o outro. Para Halliday (2014), da mesma forma, o eixo sintagmático organiza padrões do "que ocorre junto com o quê". Por outro lado, fora do discurso, na dimensão individual, os termos que podem vir a compor um enunciado se organizam em uma relação de associação na memória, evocando outros termos similares, que podem ser usados somente um por vez (SAUSSURE, 1975, p. 142). A esse "conjunto de formas léxico e construções gramaticais potencialmente realizáveis é o que Saussure chama Linguagens \& Cidadania, v. 19, número especial, jan./dez., 2017. 


\section{S Linguagens}

de língua" (NORMAND, 2009, p. 46). Na perspectiva sistêmico-funcional, essas relações são da ordem paradigmática, constituídas por uma "rede de escolhas significativas interrelacionadas" (HALLIDAY, 2014, p. 49) que o locutor tem à disposição para produzir significado.

Uma segunda aproximação diz respeito à relação entre língua e linguagem. Saussure pontua que a capacidade de "construir um sistema de signos distintos correspondentes a ideias distintas" é inerente ao ser humano (SAUSSURE, 1975, p. 18). O linguista distingue a língua como a face social de uma dimensão mais ampla - a faculdade da linguagem. Halliday (1989, p. 4) também faz essa distinção ao pontuar que a língua é um sistema dentre os inúmeros sistemas que compõe a linguagem, como por exemplo, a música, a dança, a pintura (HALLIDAY, 1989, p. 04).

Por fim, abordamos o foco que ambas orientações teóricas compartilham em relação ao recorte sincrônico. Embora não exclua a importância da diacronia no estudos das línguas, Saussure enfatiza que a análise, segundo a lei sincrônica, se ocupa do uso que os falantes fazem da língua, pois é esta realidade que conhecem ${ }^{16}$. O falante regular não tem consciência das diversas mudanças que a língua sofreu ao longo do tempo para alcançar o estado de coisas vigente. Portanto, "é no estado da língua em que se encontra o locutor comum - que não tem necessidade, para falar, de conhecer a história da língua que utiliza -, que se pode apreender o funcionamento do sistema" (NORMAND, 2000, p. 53). A teoria sistêmico-funcional, por sua vez, se orienta para o que pode ser apreendido da língua em seu contexto de uso, uma vez que o contexto no qual o texto se desenvolve "está encapsulado no texto através de uma relação sistemática entre o meio social e a organização funcional da linguagem" (FUZER; CABRAL, 2014, p. 26).

Identificadas as relações entre as perspectivas saussuriana e hallidiana, podemos dizer que a língua é tomada por Saussure como um sistema linguístico arbitrário de valores que é sincrônico e vinculado à ordem do social. Halliday compreende a língua como um sistema sociossemiotico passível de ser instanciado em textos e que se constitui em um modo de 1)

\footnotetext{
${ }^{16}$ No manuscrito Essence double du language “(...) Saussure (...) submete[r] a língua a duas instâncias distintas: a sincronia (tomar a língua em um tempo dado) e a diacronia (no tempo em geral). A distinção entre essas instâncias favoreceu a compreensão da ordem própria da língua" (SILVEIRA, 2014, p. 31).
} 


\section{S Linguagens}

agir no mundo e 2) dar e solicitar bens e serviços e informações, uma vez que envolve o estudo do significado do qual a estrutura social é constitutiva.

O conceito de sistema, para Saussure e Halliday, une-se no que tange à relação interdependente entre os termos da rede de significados. No $C G L$, isso é evidenciado quando o sistema da língua é apresentado como aquele que possui uma ordem própria, em que os valores são determinados em um dado estado de seus signos. Por sua vez, a perspectiva hallidiana demonstra essa relação ao definir sistema como um conjunto de possibilidades e significados composto pela semântica, fonologia e grafologia, sistemas esses que, além de interdependentes, estão envolvidos pelo contexto.

\section{REFERÊNCIAS}

BAILLY, C.; SÉCHEHAYE, A. Préface de la première édition. In: Cours de Linguistique Generale: edition critique. Disponível em:

$<$ http://www.clg2016.org/fileadmin/user_upload/ferdinand_de_saussure_cours_de_linguistiqu e_generale.pdf $>$. Acesso em: 9 jun. 2016.

BOUQUET, S. De um pseudo-Saussure aos textos saussurianos originais. Letras \& Letras, Uberlândia, v.25, n.01, jan./jun. 2009. p. 161-75.

CAMPOS, J. da C.; STREY, C. Inferences and Interfaces: Validity and Relevance.

Linguagem em Discurso, v.14, n.03, set./dez 2014. p. 577-594.

FIORIN, J. L. Língua e história em Saussure. Matraga, v.21, n.34, jan/jun. 2014. p. 54-72.

FLORES, V. do N. Sobre "A unidade da linguística", sobre a linguística e sobre o lingüista. Calidoscópio. v.06, n.03, set/dez 2008. p. 157-159.

FUZER, C.; CABRAL, S. R. S. Introdução à gramática sistêmico-funcional em língua portuguesa. Campinas, SP: Mercado de Letras, 2014.

HALLIDAY, M. A. K.; HASAN, R. Language, context and text: aspects of language in a social-semiotic perspective. Oxford: Oxford University Press, 1989.

HALLIDAY, M. A. K. The language of science. London/New York: Continuum, 2006.

HALLIDAY, M. A. K.; MATTHIESSEN, C. M. I. M. An introduction to functional grammar. London: Arnold, 2014. 


\section{Linguagens \& Cidadania}

NORMAND, C. Saussure. Tradução de Marcelo Diniz e Ana de Alencar. Paris: Les Belles Lettres, 2000.

Convite à linguística. Org. de Valdir do Nascimento Flores e Leci Borges Barbisan. Trad. de Cristina de Campos Velho Birck et al. São Paulo: Contexto, 2009. 204p.

OLIVEIRA, H. F. de. Onipresença de Saussure? Matraga, Rio de Janeiro, v.21, n.34, 2014. p. 37-53.

RAVELLI, L., J. Análise do espaço: adaptação e ampliação de esquemas multimodais. Matraga, v.21, n.34, jan/jun. 2014. p. 206-227.

SARGENTINI, V. M. O.; BARONAS, R. L. O Curso de Linguística Geral: apontamentos de uma leitura da Análise do Discurso. Revista do Gel, São Paulo, v.04, n.02, 2007. p. 43-52.

SAUSSURE, F. de. Curso de linguística geral. São Paulo, Cultrix, 1975, 279p.

SARDINHA, T. B. Freedom of combination and heterogeneity: a corpus linguist's look at two Saussurean insights. Matraga, v.21, n.34, jan/jun. 2014. p. 180-205.

SILVEIRA, E. O intervalo teórico de Saussure em fins do século XIX. Matraga, v.21, n.34, jan/jun. 2014. p. 25-36.

THIBAULT, P. J. Memória, coordenações associativas e sintagmáticas e microgênese linguística: implicações e prospectos para a teoria de linguagem de Saussure. Matraga, v.21, n.34, jan/jun. 2014. p. 228-279.

THOMPSON, G.; COLLINS, H. Interview with M.A.K. Halliday, Cardiff, July 1998. D.E.L.T.A., 2001, v.17, n.01, p. 131-153. Disponível em:

<http://www.scielo.br/pdf/delta/v17n1/a06v17n1.pdf>. Acesso em: 09 jun. 2016. 